\title{
Superplastic Flow and Deformation Mechanism of the Rolled Al-Mg-Li-Sc-Zr Alloy with Banded Microstructure
}

\author{
Chengzhi Zhang ${ }^{1,2}$, Yang Xiao ${ }^{1,2}$, Kaijie Ma ${ }^{2}$, Yuhan Wang ${ }^{1}$, Zhipeng Liu ${ }^{2}$, Zhenjie Liu ${ }^{2}$ and Wenjing Zhang ${ }^{3, *}$ \\ 1 School of Material Science and Engineering, Zhengzhou University, Zhengzhou 450001, China; \\ zhangchengzhi@gs.zzu.edu.cn (C.Z.); zyy_xy@rilm.com.cn (Y.X.); wyh18838915004@gs.zzu.edu.cn (Y.W.) \\ 2 Zhengzhou Light Metal Research Institute, Zhengzhou 450041, China; mkjlyx@163.com (K.M.); \\ lzp0925@126.com (Z.L.); LZJ-QYHJ@outlook.com (Z.L.) \\ 3 School of Material Science and Engineering, Tsinghua University, Beijing 100084, China \\ * Correspondence: zhangwjth@tsinghua.edu.cn; Tel.: +86-15901065952
}

check for updates

Citation: Zhang, C.; Xiao, Y.; Ma, K.; Wang, Y.; Liu, Z.; Liu, Z.; Zhang, W. Superplastic Flow and Deformation Mechanism of the Rolled Al-Mg-Li-Sc-Zr Alloy with Banded Microstructure. Metals 2021, 11, 404. https://doi.org/10.3390/met11030404

Academic Editor: Irina P. Semenova

Received: 30 January 2021

Accepted: 24 February 2021

Published: 1 March 2021

Publisher's Note: MDPI stays neutral with regard to jurisdictional claims in published maps and institutional affiliations.

Copyright: (c) 2021 by the authors. Licensee MDPI, Basel, Switzerland. This article is an open access article distributed under the terms and conditions of the Creative Commons Attribution (CC BY) license (https:// creativecommons.org/licenses/by/ $4.0 /)$.

\begin{abstract}
A hot rolled Al-5Mg-2Li-0.2Sc-0.12Zr alloy sheet with an initial banded microstructure was subjected to high-temperature tensile tests in the temperature range of $450-550{ }^{\circ} \mathrm{C}$, at strain rates ranging from $3 \times 10^{-4}$ to $1 \times 10^{-2} \mathrm{~s}^{-1}$. The microstructural evolution of the present non-ideal superplastic microstructure (banded morphology) was characterized by electron back-scattered diffraction (EBSD) and transmission electron microscopy (TEM). The results show that the hot rolled non-ideal superplastic microstructure exhibited excellent superplasticity. The optimal superplastic forming temperature appeared at $500{ }^{\circ} \mathrm{C}$ and the largest elongation of $1180 \%$ was achieved at $500{ }^{\circ} \mathrm{C}$ and $1 \times 10^{-3} \mathrm{~s}^{-1}$. As far as we know, this is the largest elongation for Al-Mg-Li-Sc-Zr alloys. The superplastic deformation of the present hot rolled banded microstructure can be divided into two stages: (i) dynamic globularization due to the dislocation movement and continuous dynamic recrystallization (CDRX), which is responsible for the plastic deformation in the low strain range; (ii) superplastic flow of the spheroidized equiaxed grains with a high ratio of high-angle grain boundaries (HAGBs) and random grain orientation in the high strain range, during which grain boundary sliding (GBS) plays the dominant role in influencing the superplastic deformation.
\end{abstract}

Keywords: Al-Mg-Li-Sc-Zr alloy; superplasticity; banded microstructure; microstructural evolution; grain boundary sliding

\section{Introduction}

The Al-Mg-Li alloy, as a structural material, has been widely used in the field of aerospace owing to it having the advantages of a low density, high specific strength, good welding performance and excellent corrosion resistance [1,2]. However, it is difficult to manufacture the complex-shaped thin-walled parts using conventional processing methods because of their poor formability, high notch sensitivity, large spring-back and easy cracking during plastic deformation at room temperature [3-5]. Alternatively, superplastic forming (SPF), as a near-net forming method, works as one of the effective methods to solve this problem and can be used to fabricate the complex-shaped structural components of the Al-Mg-Li alloy [6].

In recent years, the research on the superplasticity of the Al-Mg-Li alloy has attracted extensive attention [7-9]. Zhang et al. [10] studied the effect of a pulse current on the superplastic deformation behavior of the Al-Mg-Li alloy, suggesting that the grain nucleation was promoted and the grain growth was restrained by the electro-pulse, which improved the performance in superplasticity. Myshlyaev et al. [11] tried to improve the superplasticity of the Al-Mg-Li alloy by grain refinement using equal-channel angular pressing (ECAP). Ye et al. [7] studied the influence of the aging treatment on the superplastic flow of the Al-Mg-Li alloy and found that the over-aging treatment is beneficial to the improvement in superplasticity. What are mentioned above clearly show that the superplasticity of the 
Al-Mg-Li alloy can be improved to some extent by some appropriate technological means. However, these methods have some disadvantages in that they are difficult to achieve in the technology itself or difficult in industrialized mass production [12].

In addition, adding alloying elements to the alloys is an important way to optimize the microstructure and improve the mechanical properties including the superplasticity. Mukhopadhyay et al. [13] showed that the addition of Sc to Al alloys can refine the as-cast microstructure and inhibit the occurrence of recrystallization and refine the precipitated phase. It is more worthy to mention that the addition of both Sc and $\mathrm{Zr}$ to Al alloys can form the $\mathrm{Al}_{3}\left(\mathrm{Sc}_{\mathrm{x}}, \mathrm{Zr}_{1-\mathrm{X}}\right)$ phase, which is finer and more uniform in distribution than $\mathrm{Al}_{3} \mathrm{Sc}$ and $\mathrm{Al}_{3} \mathrm{Zr}$. Lee, $\mathrm{S}$ et al. [14] found that the Al-Mg alloy exhibits superior microstructural stability at the temperature of $500{ }^{\circ} \mathrm{C}$ by adding the Sc and $\mathrm{Zr}$ elements, eventually improving the superplasticity. Regarding the Al-Mg-Li alloy, the addition of Sc elements can not only refine the grains, but also maintain the stability of the grains at high temperatures [15]. Therefore, it is expected that the superplaticity of the Al-Mg-Li alloy can be improved by adding the Sc element.

Thermomechanical processing (TMP) plays an important role in determining the deformed microstructure, which eventually influences the superplasticity [16-18]. It is well known that, compared with the lamellar or banded microstructure (non-ideal superplastic microstructure), the equiaxed microstructure (ideal superplastic microstructure) is conductive to the achievement of superplasticity. However, P.S. Bate et al. [19] reported that the superplasticity of a rolled $\mathrm{Al}-\mathrm{Mg}-\mathrm{Cu}-\mathrm{Li}-\mathrm{Zr}$ alloy with the banded microstructure can be achieved at the temperature of $530^{\circ} \mathrm{C}$, at the strain rate of $5 \times 10^{-4} \mathrm{~s}^{-1}$. The authors attributed this phenomenon to the dynamic recrystallization (DRX) that occurred during the superplastic tensile deformation, resulting in the equiaxed microstructure obtained in the fractured sample, which promotes the grain boundary slip (GBS) to operate and the ultimate achievement of superplasticity. R. Kaibyshev et al. [20] found that superplasticity can also be achieved in the Al-Mg-Sc alloy with a partially recrystallized structure at the temperature of $520^{\circ} \mathrm{C}$, at the strain rate of $5.6 \times 10^{-2} \mathrm{~s}^{-1}$. Although some investigations have been conducted to study the superplastic deformation behavior of the lamellar or banded microstructure of $\mathrm{Al}$ alloys, there are still limitations in systematically studying the superplastic deformation behavior and the microstructural evolution of these non-ideal superplastic microstructures of $\mathrm{Al}$ alloys.

Accordingly, in the present study, the Sc element was added to the $\mathrm{Al}$ alloy, and then Al-Mg-Li-Sc-Zr alloy sheets were processed by hot rolling to obtain the banded microstructure. Subsequently, superplastic tensile tests and microstructural observation were conducted. The present aim is to explore the superplastic deformation behavior and clarify the superplastic deformation mechanism of a hot rolled Al-Mg-Li-Sc-Zr alloy with a non-ideal superplastic microstructure.

\section{Experimental Material and Procedures}

The present experimental alloy was cast in an induction furnace under an argon atmosphere. Pure aluminum of $99.99 \%$, pure magnesium of $99.95 \%$ and pure lithium of $99.90 \%$, along with master alloys $\mathrm{Al}-2 \% \mathrm{Sc}$ and $\mathrm{Al}-10 \% \mathrm{Zr}$, were used for alloy preparation. All concentrations are given in wt.\%. The raw material of the alloy was smelted in a high-purity graphite crucible and poured into an iron mold under the protection of the argon atmosphere in a vacuum furnace. The mass fraction of the alloy resulted as $\mathrm{Al}-5.0 \mathrm{Mg}$ $2.0 \mathrm{Li}-0.2 \mathrm{Sc}-0.12 \mathrm{Zr}$ when analyzed and measured by inductively coupled plasma (ICP). The cast ingot was hot rolled into plates with a thickness of $10 \mathrm{~mm}$. Subsequently, these plates were subjected to solution treatment for $2 \mathrm{~h}$ at $470{ }^{\circ} \mathrm{C}$, followed by over-aging treatment for $48 \mathrm{~h}$ at $300{ }^{\circ} \mathrm{C}$. The heat-treated plates were then hot rolled for several passes with a reduction of $15 \%$ per pass to the final thickness of $2 \mathrm{~mm}$ at the temperature of $400{ }^{\circ} \mathrm{C}$. With respect to the hot rolling, the pre-heat treatment was conducted for $1 \mathrm{~h}$ at $400{ }^{\circ} \mathrm{C}$ before the hot rolling. Moreover, the rolling plates with a reduction of $53 \%$ were tempered for $0.5 \mathrm{~h}$ at $400{ }^{\circ} \mathrm{C}$. For the specific procedures for preparing the material, please see Figure 1. 


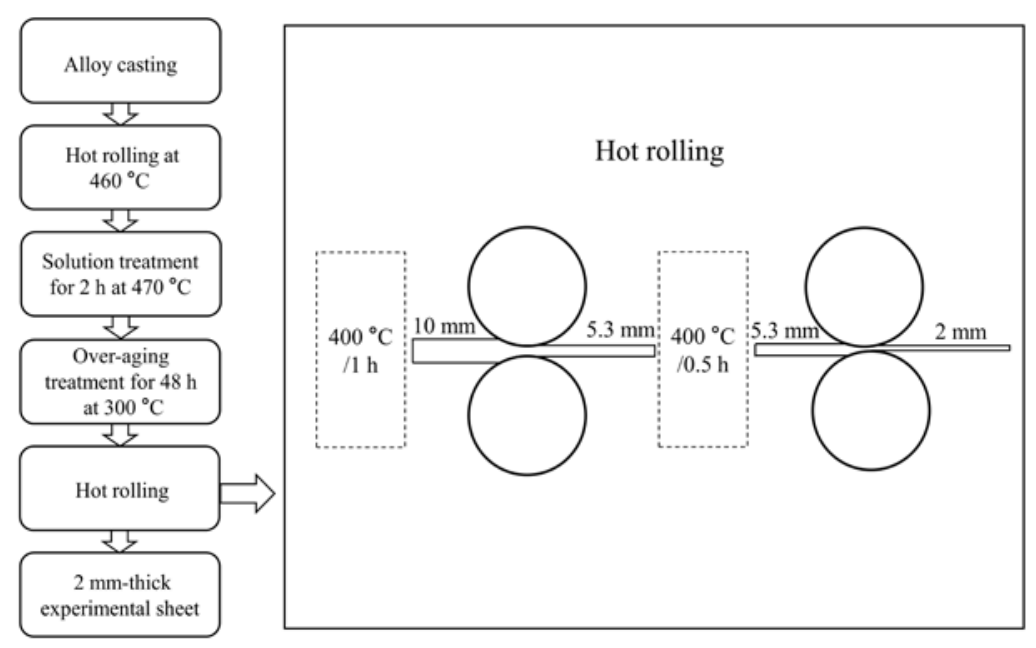

Figure 1. Schematic illustration for preparing the hot rolled Al-5Mg-2Li-0.2Sc-0.12Zr alloy sheet.

The tensile specimens were cut from the hot rolled sheets parallel to the rolling direction (RD) by an electrical discharge machine (EDM), and the specific shape and size of the tensile samples are shown in Figure 2. The uniaxial tensile tests with a constant initial strain rate were carried out on the Electronic Universal Testing Machine (CRIMS, Changchun, China) equipped with a heating device. The tensile specimens were ground using $\mathrm{SiC}$ emery papers of up to 3000 grit to remove the oxide film on the surface of the samples, and eventually tensile samples with $2 \mathrm{~mm}$ thickness were obtained. Before the tensile testing, the tensile samples were heated to the target temperature and held for $20 \mathrm{~min}$ to ensure the thermal equilibrium of the samples. Tensile tests were performed at strain rates ranging from $3 \times 10^{-4}$ to $1 \times 10^{-2} \mathrm{~s}^{-1}$ in the temperature range of $450-550{ }^{\circ} \mathrm{C}$.

\section{Tensile sample}

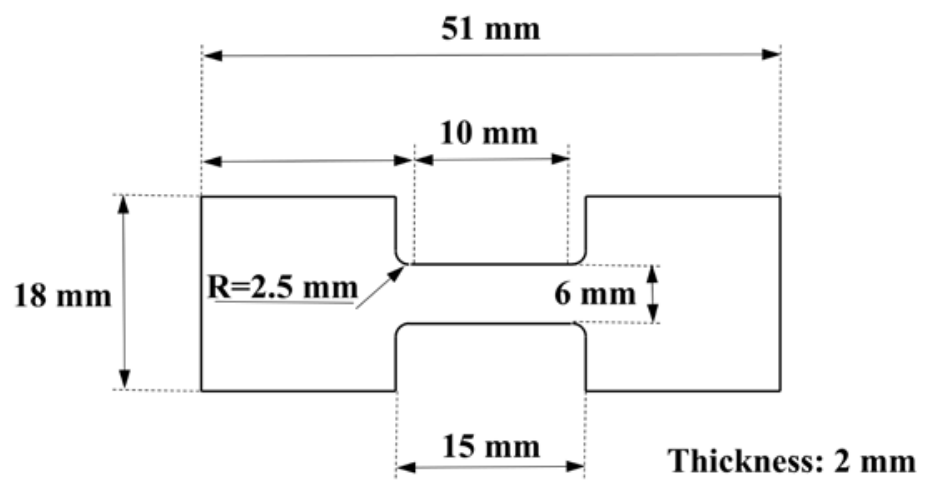

Figure 2. The specific shape and size of the tensile sample.

The microstructure was characterized by electron back-scattered diffraction (EBSD) and transmission electron microscopy (TEM). The EBSD samples were polished using $\mathrm{SiC}$ emery paper and then electropolished in electrolyte solution of $10 \% \mathrm{HClO}_{4}$ and $90 \%$ $\mathrm{C}_{2} \mathrm{H}_{5} \mathrm{OH}$ for $25 \mathrm{~s}$ at the voltage of $25 \mathrm{~V}$. The EBSD characterization was conducted using a field emission gun scanning electron microscope (JEOL JSM-7800F, Tokyo, Japan) equipped with the Nordlys Nano EBSD system, and the scanning step size was $0.5 \mu \mathrm{m}$. The foils for TEM characterization were prepared by twin-jet electropolishing in an electrolyte solution consisting of $30 \%$ nitric acid and $70 \%$ methanol at a temperature of below $-20{ }^{\circ} \mathrm{C}$ with the voltage of $20 \mathrm{~V}$ and electricity of $60 \mathrm{~mA}$. 


\section{Results}

\subsection{Microstructure of the Al-5Mg-2Li-0.2Sc-0.12Zr Alloy after Hot Rolling}

Figure 3 shows the EBSD map of the Al-5Mg-2Li-0.2Sc-0.12Zr alloy sheet after hot rolling, where the different colors represent different grain orientations: the white line represents the low-angle grain boundaries $\left(2^{\circ}<\right.$ LAGBs $\left.<15^{\circ}\right)$, whereas the black line represents the high-angle grain boundaries (HAGBs $>15^{\circ}$ ) - these representations also apply to the subsequent EBSD maps. It can be seen that the microstructure after hot rolling shows an elongated morphology and a strong texture. The long axis of this elongated microstructure distributes along the $\mathrm{RD}$. The length of these elongated microstructures is about a dozen microns, whereas the width is just about several microns, demonstrating typical rolled microstructural characteristics with a large aspect ratio. In addition, it can be calculated that the ratio of LAGBs is high, at $47.1 \%$. This is because the dynamic recovery (DRV), occurred during the hot rolling.

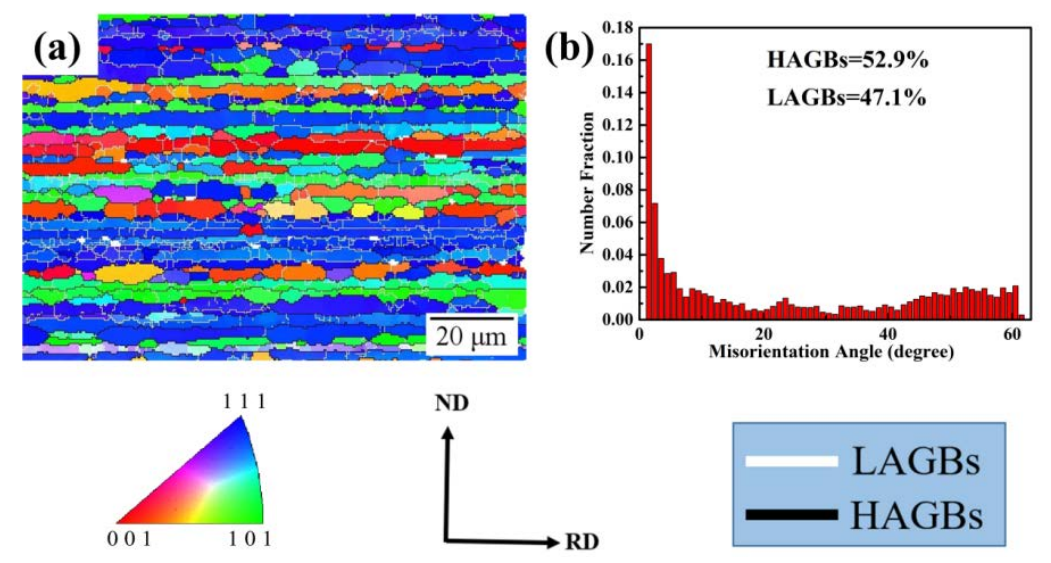

Figure 3. EBSD maps of the hot rolled Al-5Mg-2Li-0.2Sc-0.12Zr alloy: (a) IPF map, (b) misorientation angle distribution histogram.

\subsection{Superplastic Deformation Behavior}

\subsubsection{Elongation to Failure}

Superplastic tensile tests were conducted in the hot rolled Al-Mg-Li-Sc-Zr alloy at a temperature ranging from 450 to $550{ }^{\circ} \mathrm{C}$, at the strain rates of $3 \times 10^{-4} \sim 1 \times 10^{-2} \mathrm{~s}^{-1}$. The variations in elongations against the strain rates at the temperatures of 450,475, 500, 525 and $550{ }^{\circ} \mathrm{C}$ are shown in Figure 4. It can be seen that except for the elongations of $354 \%$ and $369 \%$ obtained at the temperatures of 450 and $550{ }^{\circ} \mathrm{C}$, at the strain rate of $3 \times 10^{-4} \mathrm{~s}^{-1}$, nearly all the samples exhibit excellent superplasticity with elongations above the superplastic-critical elongation of $400 \%$ [21], and the largest elongation of $1180 \%$ was achieved at $500{ }^{\circ} \mathrm{C}$ and $1 \times 10^{-3} \mathrm{~s}^{-1}$. Herein, it should be noted that even at the high strain rate of $1 \times 10^{-2} \mathrm{~s}^{-1}$, the large elongation was obtained in the present hot rolled microstructure. All of these demonstrate that the present hot rolled Al-5Mg-2Li-0.2Sc$0.12 \mathrm{Zr}$ alloy with the non-ideal superplastic microstructure (banded morphology) can still show excellent superplasticity.

In addition, the tensile fractured samples at different strain rates at the temperature of $500{ }^{\circ} \mathrm{C}$ are shown in Figure 5a, whereas those at different temperatures at the strain rate of $1 \times 10^{-3} \mathrm{~s}^{-1}$ are shown in Figure $5 \mathrm{~b}$. It can be seen that the temperatures and strain rates play important roles in determining the superplasticity. The elongations firstly increase and then decrease with the increasing strain rate, and the optimal strain rate for the present hot rolled Al-Mg-Li-Sc-Zr alloy at $500{ }^{\circ} \mathrm{C}$ appears at $1 \times 10^{-3} \mathrm{~s}^{-1}$, as shown in Figure $5 \mathrm{a}$, which is consistent with the previous superplastic tensile results where the optimal superplasticity was obtained at an intermediate strain rate [9]. This is because the GBS is the predominant deformation mechanism for superplasticity, and it is not conductive for the GBS and the achievement of superplasticity at the too low or too high strain rate. Furthermore, the 
elongations firstly increase and then decrease with the increasing temperature, and the optimal superplastic temperature at $1 \times 10^{-3} \mathrm{~s}^{-1}$ appears at $500^{\circ} \mathrm{C}$, as shown in Figure $5 \mathrm{~b}$. This is because the energy for the GBS supplied at the low temperature is lower than that the high temperature, and thus the GBS contributes more to the superplasticity at the high temperature. However, when the temperature increases too much up to 525 and $550{ }^{\circ} \mathrm{C}$, severe grain growth may occur during tensile formation, which is harmful to the GBS and the relevant accommodated mechanism (dislocation and/or diffusion accommodation) working during tensile deformation. Moreover, as the temperature increases, the amount of black oxide film on the sample surface increases gradually, and this is another reason why the elongation decreases when the tensile deformation temperature elevates to 525 and $550{ }^{\circ} \mathrm{C}$.

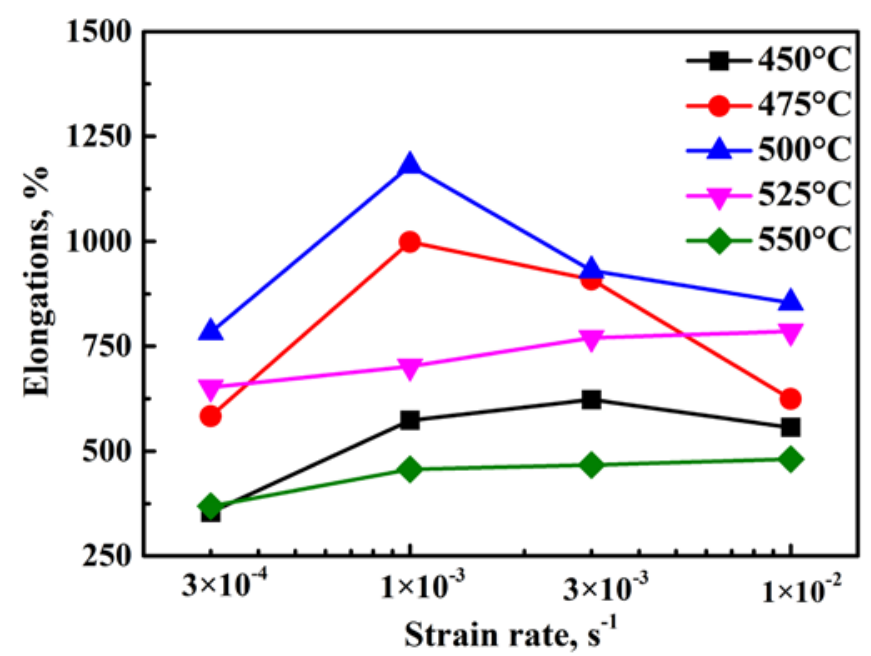

Figure 4. The variations in elongations against the strain rates at the temperatures of 450, 475, 500, 525 and $550{ }^{\circ} \mathrm{C}$.

(a)

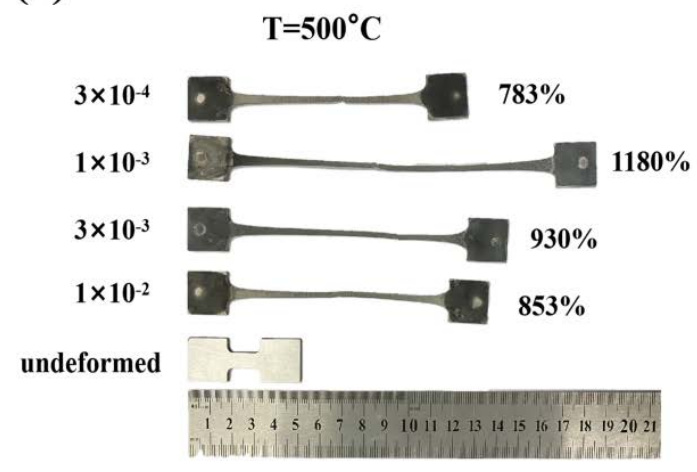

(b)

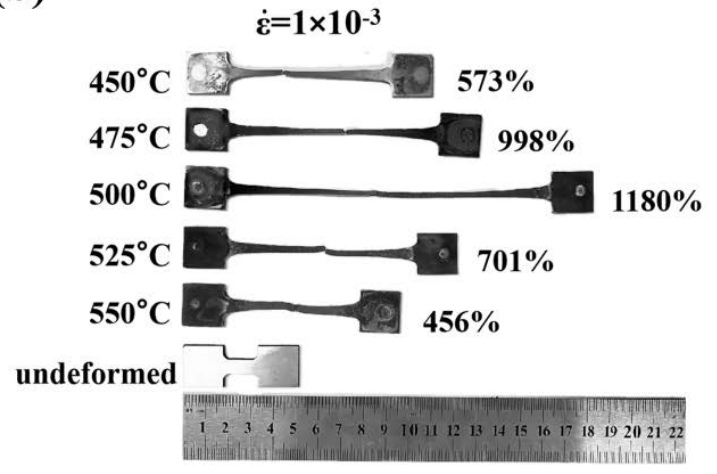

Figure 5. The tensile fractured samples, (a) at different strain rates at $500{ }^{\circ} \mathrm{C} ;(\mathbf{b})$ at different temperatures at $1 \times 10^{-3} \mathrm{~s}^{-1}$.

\subsubsection{True Stress-True Strain Curves}

The typical true stress-true strain curves in the strain rate range of $3 \times 10^{-4} \sim 1 \times 10^{-2} \mathrm{~s}^{-1}$ at $500{ }^{\circ} \mathrm{C}$ are shown in Figure $6 \mathrm{a}$, whereas those at the temperature ranging from 450 to $550{ }^{\circ} \mathrm{C}$ at $1 \times 10^{-3} \mathrm{~s}^{-1}$ are displayed in Figure $6 \mathrm{~b}$. It can be found that, at the high strain rate of $1 \times 10^{-2} \mathrm{~s}^{-1}$ (Figure 6a) or low temperature of $450{ }^{\circ} \mathrm{C}$ (Figure $6 \mathrm{~b}$ ), the flow stress increases dramatically and reaches the peak point very fast, and then decreases gradually until the fracture. This phenomenon occurs because of the extensive initial strain hardening followed by subsequent dynamic flow softening [22]. However, as the strain rate decreases to $3 \times 10^{-3} \mathrm{~s}^{-1}$ (Figure 6a) or the temperature increases to $475{ }^{\circ} \mathrm{C}$ (Figure $6 \mathrm{~b}$ ), the flow stress increases rapidly to the peak point, and then a stable stage is observed, displaying a 
typical superplastic flow, wherein the dynamic work hardening and dynamic softening are dynamically balanced and the GBS is the predominant deformation mechanism.

(a)

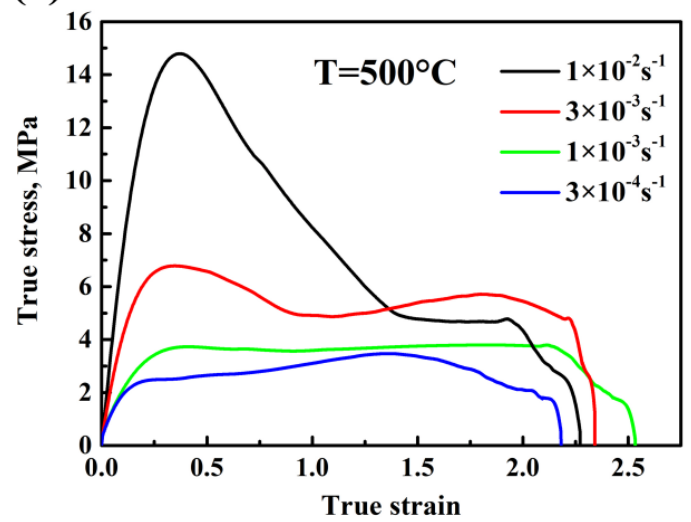

(b)

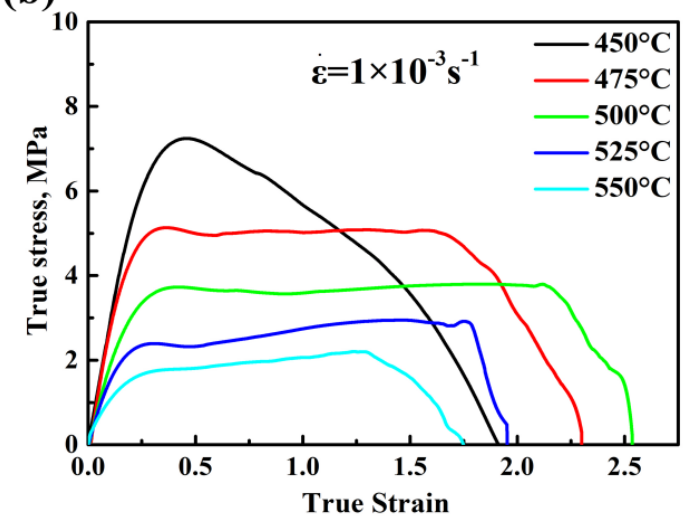

Figure 6. The true stress-true strain curves, (a) at different strain rates at $500{ }^{\circ} \mathrm{C} ;(\mathbf{b})$ at different temperatures at $1 \times 10^{-3} \mathrm{~s}^{-1}$.

\subsubsection{Strain Rate Sensitivity}

Backofen proposed the concept of the strain rate sensitivity index, $\mathrm{m}$ value, which is an important parameter in superplastic deformation and can reflect the capability of resistance to necking [23]. It is defined as the function of the natural logarithmic values of stress and strain as

$$
\mathrm{m}=\frac{\partial \ln \sigma}{\partial \ln \dot{\varepsilon}}
$$

In general, the higher the $\mathrm{m}$ value, the better the obtained superplasticity. The curves of $\ln \sigma$ vs. $\ln \dot{\varepsilon}$ in the temperature range of $450-550{ }^{\circ} \mathrm{C}$ and strain rate range of $3 \times 10^{-4} \sim 1 \times 10^{-2} \mathrm{~s}^{-1}$ are shown in Figure $7 \mathrm{a}$, the slopes of which represent the strain rate sensitivity of the superplastic flow. The true stress values corresponding to the true strain of 0.4 were utilized for the calculation of the $m$ values. The results show that the $m$ values of the present hot rolled Al-Mg-Li-Sc-Zr alloy are between 0.31 and 0.57 and the average $\mathrm{m}$ value is 0.49 . Such high $\mathrm{m}$ values restrained the of necking during the superplastic tensile deformation, and thus the present hot rolled microstructure shows excellent superplasticity. In addition, it can be found that the $m$ values first increase and then decrease with the increasing strain rate, which is responsible for the tensile tensing results where the largest elongation was achieved at the intermediate strain rate, as mentioned above. As for the effect of temperature on the $m$ value, it is obvious that the $m$ value at the temperature of $500{ }^{\circ} \mathrm{C}$ is higher than that obtained at the other temperatures, as shown in Figure $7 \mathrm{a}$, which corresponds to result where the maximum elongation of $1180 \%$ appears at $500{ }^{\circ} \mathrm{C}$.

In order to reveal the superplastic deformation behavior under the optimal deformation condition $\left(500^{\circ} \mathrm{C}, 1 \times 10^{-3} \mathrm{~s}^{-1}\right)$, strain rate jump tests were employed to evaluate the strain rate sensitivity parameter ( $m$ value), and the changing tendency of the $m$ value against the true strain is displayed in Figure $7 \mathrm{~b}$. It can be seen that the $\mathrm{m}$ value remains at a low level below 0.41 when the engineering strain is lower than $50 \%$ (true strain, 0.4 ); after that, the $\mathrm{m}$ value gradually increases to 0.56 with the increasing engineering strain to $101 \%$ (true strain, 0.7 ), and then it tends to be stable with the strain further increasing. The related reasons for the present changing tendency of the $m$ value will be discussed in detail in the following section.

\subsection{The Microstructure in the Grip and Gauge Section}

In order to reveal the influence of the single factor of strain on the microstructure, the grip section and the gauge section microstructures of the tensile fractured sample with elongation of $1180 \%$ are shown in Figure 8a,b, respectively. The grip section is only 
subjected to heat, whereas the gauge section is affected by both heat and strain. In the present study, the grip section is equivalent to that after high-temperature annealing at $500{ }^{\circ} \mathrm{C}$ for $3.61 \mathrm{~h}$. It can be seen that after static annealing treatment, although the microstructure has the characteristics of a rolled structure, some equiaxed grains appear around the banded structure. Compared with the initial hot rolled microstructure shown in Figure 3, the LAGBs ratio of the grip section microstructure decreases from $47.1 \%$ to $42.3 \%$, indicating that incomplete recrystallization in the rolled microstructure occurred during the subsequent high-temperature annealing. In addition, the gauge section microstructure in Figure 8b displays an equiaxed morphology with a high ratio of HAGBs (92.1\%) and random crystallographic orientations, which is consistent with the microstructural characteristics in the conventional superplastic deformed microstructure [24], suggesting that DRX may occur during the high-temperature tensile deformation and the GBS is the predominant deformation mechanism in the present study. Furthermore, the grain size of $6.6 \mu \mathrm{m}$ in the gauge section microstructure is higher than that of $4.4 \mu \mathrm{m}$ in the grip section microstructure. This is because the application of stress can promote grain boundary migration, grain rotation and grain coalescence, eventually resulting in grain growth $[13,25,26]$.

(a)

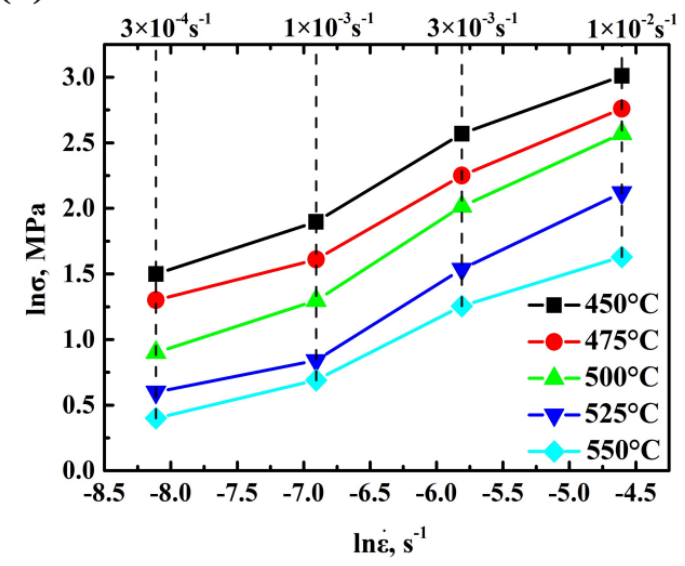

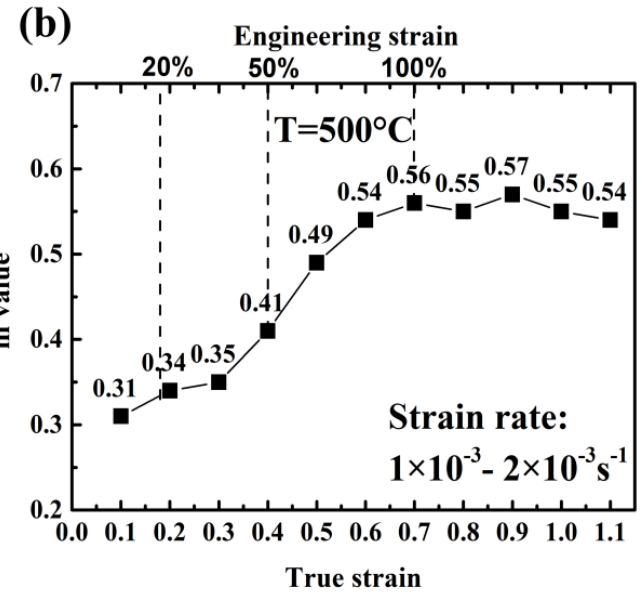

Figure 7. (a) The curves of $\ln \sigma$ vs. $\ln \dot{\varepsilon}$ in the temperature range of $450-550{ }^{\circ} \mathrm{C}$, at strain rates ranging from $3 \times 10^{-4}$ to $1 \times 10^{-2} \mathrm{~s}^{-1} ;(\mathbf{b})$ the changing trend of the strain rate sensitivity of the superplastic flow, $\mathrm{m}$ values, against the strain within the strain rate range of $1 \times 10^{-3} \sim 2 \times 10^{-3} \mathrm{~s}^{-1}$.
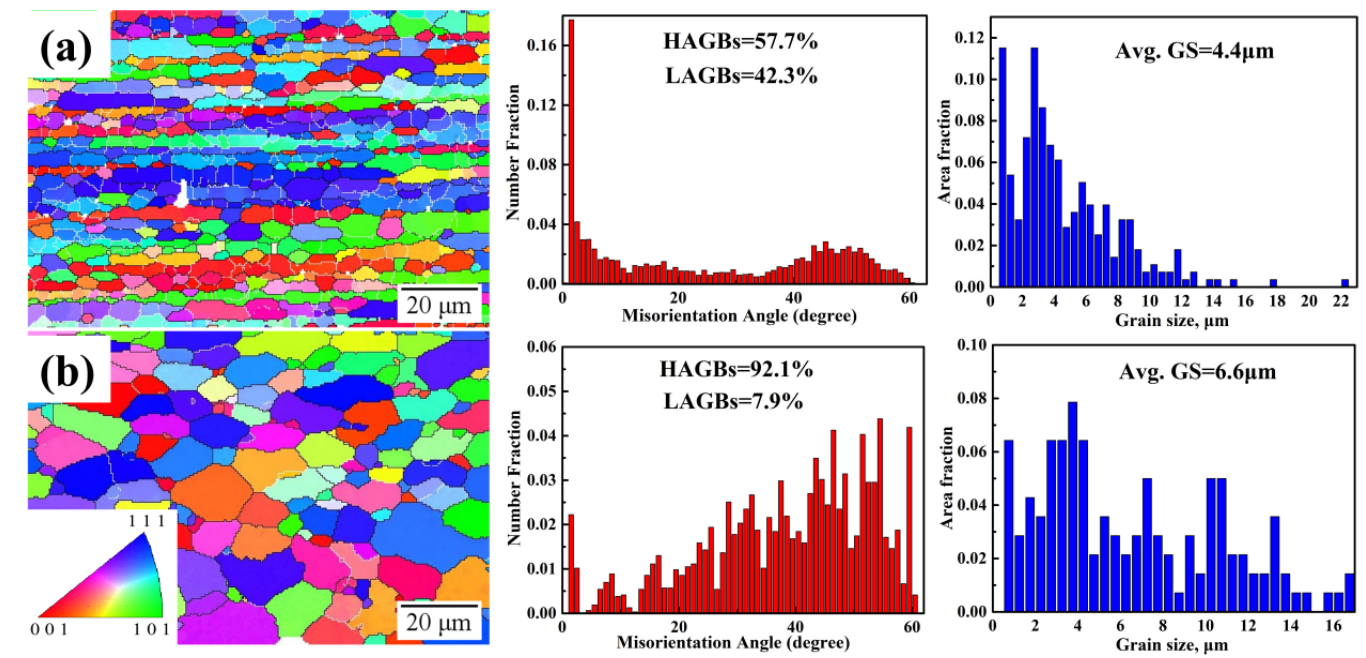

Figure 8. The microstructure of the tensile fractured sample with the engineering strain of 1180\%: (a) grip section; (b) gauge section. 


\section{Discussion \\ 4.1. Significance of the Hot Rolling}

Rolling, as a common engineering technology, has been widely used for microstructural modification in order to improve the mechanical properties and expand the application of materials. Generally, the lower the rolling temperature, the greater storage energy obtained, which is conducive to the dynamic and/or static recrystallization in the rolled microstructure during the subsequent TMP and/or heat treatment. However, the present Al-5Mg-2Li-0.2Sc-0.12Zr alloy is easy to crack during cold rolling because of the poor workability at room temperature. Alternatively, hot rolling at the temperature of $400{ }^{\circ} \mathrm{C}$ was utilized in the present study. The microstructure after hot rolling is shown in Figures 3 and 9. There is a large amount of dislocation and dislocation tangling, as shown in Figure 9. In the present study, because of the Sc element added to the alloy, the hard phase containing the Sc element formed, which can be proved by the energy disperse spectroscopy (EDS) analysis. Based on the present EDS results and the previous research results by other researchers [18], this hard phase is most likely to be $\mathrm{Al}_{3}\left(\mathrm{Sc}_{\mathrm{x}}, \mathrm{Zr}_{1-\mathrm{X}}\right)$. The existence of this hard phase can inhibit the dislocation movement and accelerate the dislocation pile-up and tangling during hot rolling. Thus, a high ratio of LAGBs of $47.1 \%$ was obtained in the hot rolled microstructure, as shown in Figure 3. These microstructural characteristics can supply enough storage energy for the dynamic globularization and grain refinement during the subsequent high-temperature tensile deformation. This is beneficial to the achievement and improvement of the present superplasticity of the hot rolled microstructure.
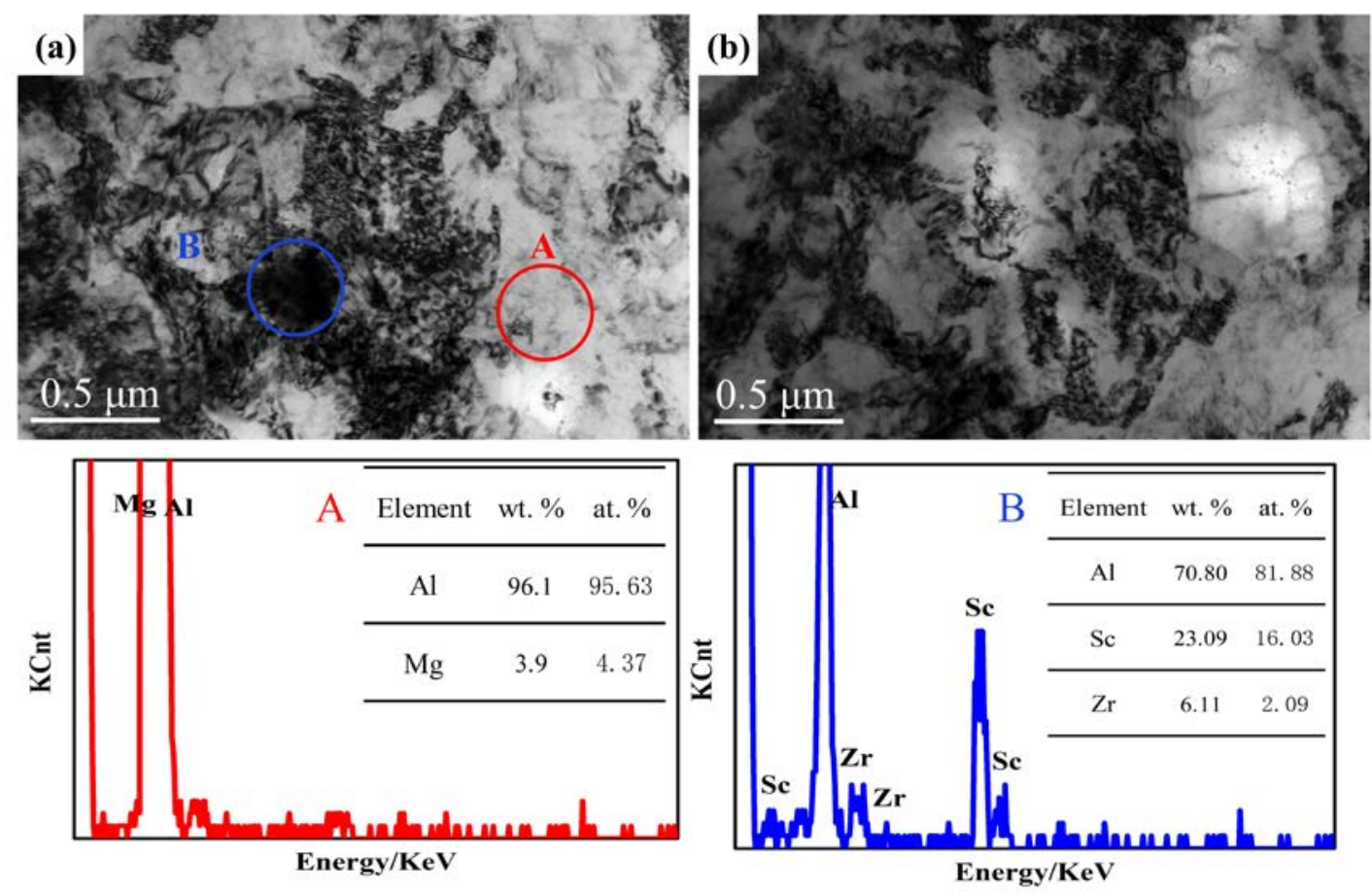

Figure 9. The TEM maps of the hot rolled Al-5Mg-2Li-0.2Sc-0.12Zr alloy, (a) and (b) are the different positions of the rolled microstructure.

\subsection{Superplastic Deformation Mechanism}

Generally, a superplastic deformation microstructure is characterized by equiaxed and fine-grained microstructure with a high ratio HAGBs [27]. However, some researchers have also reported [28-30] that superplasticity can be achieved in the elongated, banded or even lamellar microstructures. In the present study, the gauge section microstructure of the tensile fractured sample shows that the initial hot rolled banded microstructure was replaced by equiaxed grains with a random crystallographic orientation. In addition, 
the ratio of HAGBs increased and the texture was weakened. These changes are similar to those reported in Al-Mg-Sc alloy [26] and AA7010 alloy [15]. Most studies presumed that when the initial microstructure is not the ideal superplastic microstructure (equiaxed morphology), such as the banded structure or the lamellar morphology, the superplastic tensile deformation can be divided into the following two stages [13,30]. The first stage is considered as dynamic globularization, mainly resulting from the DRX in the low strain range. When the dynamic globularization is completed, the deformation evolves into the second stage, where, now, the spheroidized equiaxed microstructure is obtained and the dominant deformation mechanism is GBS [31-36].

In order to clarify and reveal the superplastic deformation mechanism in the present hot rolled $\mathrm{Al}-5 \mathrm{Mg}-2 \mathrm{Li}-0.2 \mathrm{Sc}-0.12 \mathrm{Zr}$ alloy, and the gauge section microstructures interrupted at the engineering strains of $20 \%, 50 \%, 100 \%$ and $500 \%$ at $500{ }^{\circ} \mathrm{C}$ and $1 \times 10^{-3} \mathrm{~s}^{-1}$ were characterized using EBSD, as shown in Figure 10, and the microstructural evolution was explored. The grain size, aspect ratio and fraction of HAGBs are three important parameters in describing the microstructural evolution, and the statistical results are shown in Table 1.
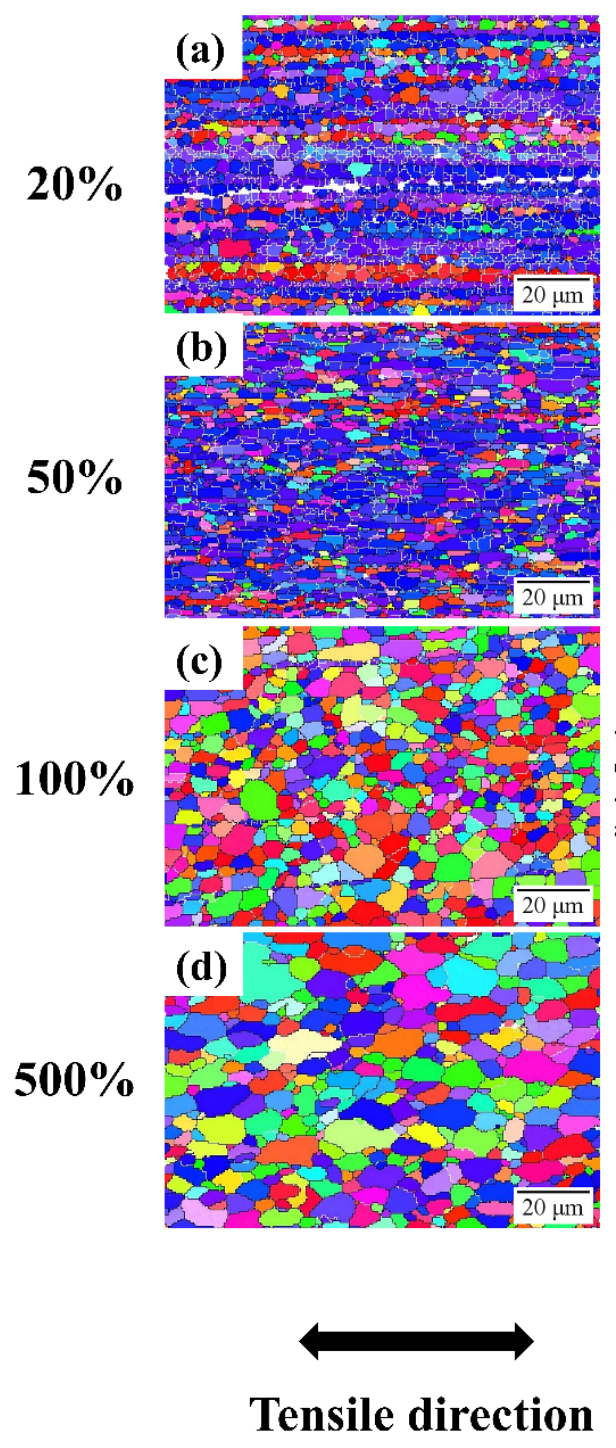
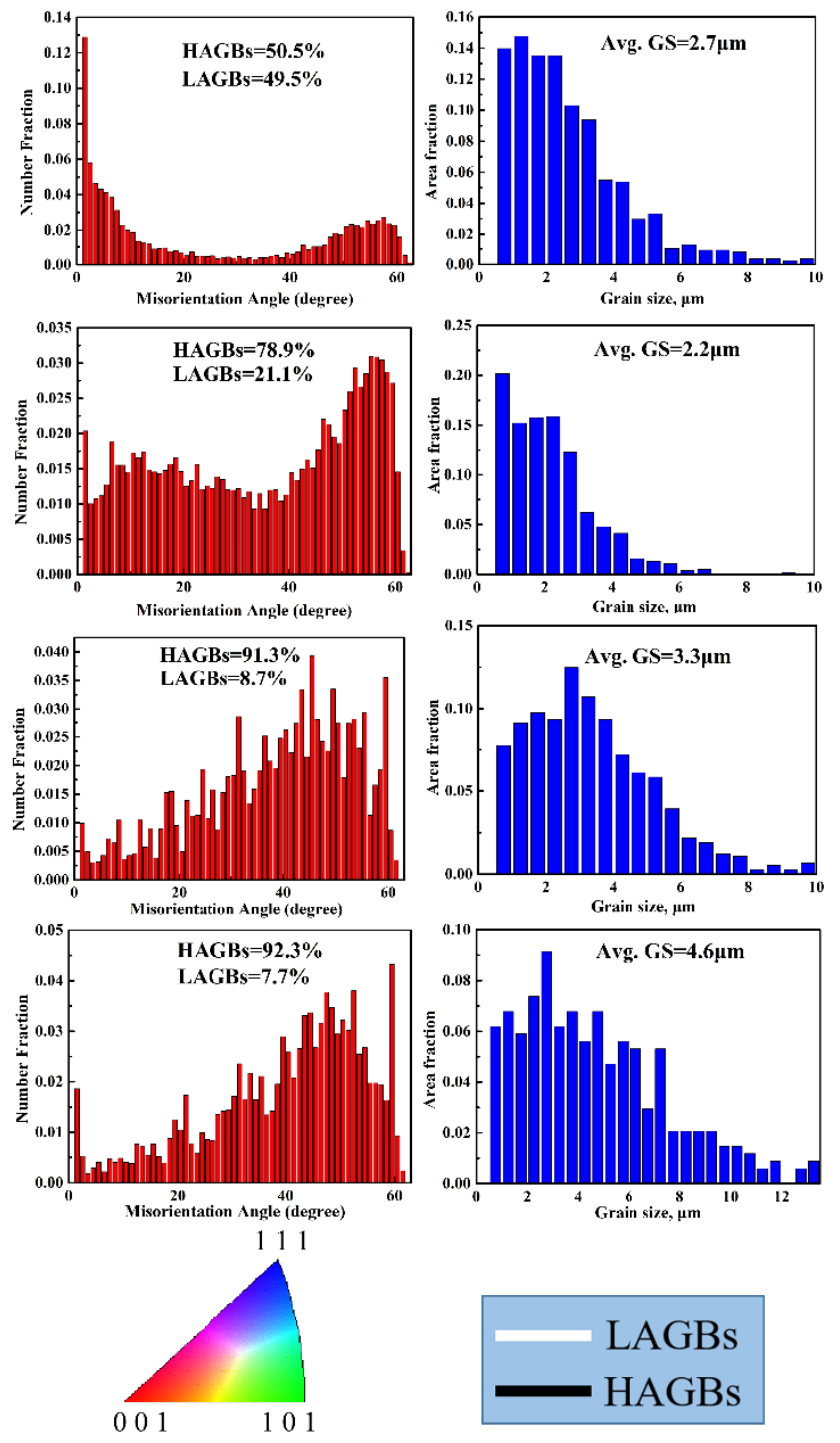

\section{LAGBs} HAGBs

Figure 10. IPF maps of the gauge section microstructure tested at $1 \times 10^{-3} \mathrm{~s}^{-1}$ and $500{ }^{\circ} \mathrm{C}$ with different engineering strains of (a) 20\%, (b) 50\%, (c) 100\% and (d) 500\%. Here, the misorientation angle histograms and grain size histograms corresponding to different engineering strains of $20 \%, 50 \%, 100 \%$ and $500 \%$ are shown at the right side. 
Table 1. Several specific microstructural parameters of the gauge section microstructure with different engineering strains at the optimal superplastic conditions of $500{ }^{\circ} \mathrm{C}$ and $1 \times 10^{-3} \mathrm{~s}^{-1}$.

\begin{tabular}{ccccccc}
\hline \multirow{2}{*}{$\begin{array}{c}\text { Engineering } \\
\text { Strain }\end{array}$} & \multicolumn{3}{c}{ Grain Size/ $\mu \mathrm{m}$} & $\begin{array}{c}\text { Proportion of } \\
\text { HAGBs/\% }\end{array}$ & $\begin{array}{c}\text { Proportion of } \\
\text { LAGBs/\% }\end{array}$ \\
\cline { 2 - 5 } $\mathbf{d}_{\mathbf{R D}}$ & $\mathbf{d}_{\text {ND }}$ & Average & Aspect Ratio & & 52.9 & 47.1 \\
$0 \%$ & 11.3 & 2.6 & 6.8 & 4.3 & 50.5 & 49.5 \\
$20 \%$ & 3.5 & 1.6 & 2.7 & 2.2 & 78.9 & 21.1 \\
$50 \%$ & 3.3 & 1.7 & 2.2 & 1.9 & 91.6 & 8.4 \\
$100 \%$ & 5 & 3.0 & 3.3 & 1.7 & 92.3 & 7.7 \\
$500 \%$ & 5.5 & 3.7 & 4.6 & 1.5 & 92.1 & 7.9 \\
$1180 \%$ & 7.4 & 5.6 & 6.6 & 1.3 & \\
\hline
\end{tabular}

\subsubsection{First Stage}

At the engineering strain of $20 \%$, the microstructure still exhibits the typical elongated morphology, but there appears to be some equiaxed fine grains around the elongated grains, as shown in Figure 10a. As the engineering strain increases to $50 \%$, the volume fraction of the elongated grains decreases, whereas the equiaxed grains are elevated, as shown in Figure 10b. The ratio of LAGBs decreases from $49.5 \%$ to $21.1 \%$ with the strain increasing from $20 \%$ to $50 \%$, demonstrating that the sub-grains evolved into grains with HAGBs and continuous dynamic recrystallization (CDRX) may occur during the hightemperature tensile deformation, which is responsible for the increase in the volume fraction of equiaxed grains. In addition, the microstructures at the low strains of $20 \%$ and $50 \%$ show a strong texture, which was also reported by Sotoudeh and coworkers [37], but the maximum intensity is reduced as the strain increases from $20 \%$ to $50 \%$. It can be inferred from the microstructural characteristics at the low strain mentioned above that GBS is not the predominant but the dislocation movement and CDRX contribute the plastic deformation. This can explain why the $m$ values at the low strain are relatively low, as shown in Figure $7 \mathrm{~b}$.

\subsubsection{Second Stage}

As the engineering strain increases to $100 \%$, the initial banded microstructure disappears and is replaced by nearly fully equiaxed grains, and the average grain size is $3.3 \mu \mathrm{m}$, as shown in Figure 10c. The ratio of HAGBs is relatively high at $91.3 \%$, corresponding to the ratio of LAGBs being low at $8.7 \%$. In addition, the texture of the microstructure weakens, and it shows almost random crystallographic orientations. This suggests that the GBS is the predominant superplastic deformation mechanism, which can evidence the reason why the $m$ value increases to nearly the maximum of 0.56 at the engineering strain of $100 \%$, as shown in Figure $7 \mathrm{~b}$.

As the engineering strain increases from $100 \%$ to $500 \%$ and even to $1180 \%$, the microstructure still shows an equiaxed morphology with random crystallographic orientations. The ratios of HAGBs maintain a high value of $92.3 \%$ and $92.1 \%$ at the engineering strains of $500 \%$ and $1180 \%$, as shown in Figures $8 \mathrm{~b}$ and $10 \mathrm{~d}$, respectively. All of these microstructural characteristics attest that the GBS plays a dominant role during the tensile deformation. In addition, the average grain size grows from 3.3 at the engineering strain of $100 \%$ to $4.6 \mu \mathrm{m}$ at $500 \%$ and $6.6 \mu \mathrm{m}$ at $1180 \%$, indicating that the grain growth occurred under the combined effect of heat and stress. Grain growth is the common phenomenon during superplastic tensile deformation, which, to some extent, results in work hardening, and this can explain why the true stress-true strain curves may upwarp, such as the true stress-true strain curves at $3 \times 10^{-4} \mathrm{~s}^{-1}$ and $500{ }^{\circ} \mathrm{C}$ and $1 \times 10^{-3} \mathrm{~s}^{-1}$ and $525^{\circ} \mathrm{C}$, as well as $1 \times 10^{-3} \mathrm{~s}^{-1}$ and $550{ }^{\circ} \mathrm{C}$.

In other words, the first stage of the present superplastic deformation is dominated by the dynamic globularization of the banded microstructure, whereas the second stage is mainly governed by the GBS of the spheroidized equiaxed grains. 


\section{Conclusions}

A hot rolled Al-5Mg-2Li-0.2Sc-0.12Zr alloy sheet was subjected to high-temperature tensile tests. The superplastic deformation behavior was studied. In order to reveal the superplastic deformation mechanism, the microstructural evolution was analyzed. The main conclusions are as follows:

1. The hot rolled Al-5Mg-2Li-0.2Sc-0.12Zr alloy with the non-ideal superplastic microstructure (banded microstructure) proved to be excellent in the performance of superplasticity. The optimal superplastic forming temperature appeared at $500{ }^{\circ} \mathrm{C}$ and the largest elongation of $1180 \%$ was achieved at $500{ }^{\circ} \mathrm{C}$ and $1 \times 10^{-3} \mathrm{~s}^{-1}$. As far as we know, this is the largest elongation for Al-Mg-Li-Sc-Zr alloys.

2. It is difficult for the hot rolled $\mathrm{Al}-5 \mathrm{Mg}-2 \mathrm{Li}-0.2 \mathrm{Sc}-0.12 \mathrm{Zr}$ alloy to fully recrystallize only under the condition of heat treatment. However, under the combined action of heat and stress during high-temperature tensile deformation, fully dynamic recrystallization (DRX) of the present alloy can occur, resulting in the initial hot rolled banded microstructure evolving into an equiaxed microstructure.

3. The superplastic deformation of the present hot rolled Al-5Mg-2Li-0.2Sc-0.12Zr alloy with an initial banded microstructure can be divided into two stages: (i) dynamic globularization due to the dislocation movement and continuous dynamic recrystallization (CDRX), which is responsible for the plastic deformation in the low strain range; (ii) superplastic flow of the spheroidized equiaxed grains with a high ratio of HAGBs and random grain orientation in the high strain range, during which grain boundary sliding (GBS) plays the dominant role in influencing the deformation.

Author Contributions: Conceptualization, C.Z.; methodology, C.Z., Y.W. and W.Z.; formal analysis, K.M., Z.L. (Zhipeng Liu), Z.L. (Zhenjie Liu); investigation, C.Z. and Y.W.; writing-original draft preparation, C.Z.; writing-review and editing, W.Z.; supervision, W.Z. and Y.X.; project administration, Z.L. (Zhipeng Liu). All authors have read and agreed to the published version of the manuscript.

Funding: This research received no external funding.

Institutional Review Board Statement: Not applicable.

Informed Consent Statement: Not applicable.

Data Availability Statement: The raw/processed data required to reproduce these findings cannot be shared at this time as the data also form part of an ongoing study.

Conflicts of Interest: The authors declare no conflict of interest.

\section{References}

1. Betsofen, S.Y.; Antipov, V.V.; Knyazev, M.I. Al-Cu-Li and Al-Mg-Li Alloys: Phase Composition, Texture, and Anisotropy of Mechanical Properties. Russ. Metall. 2016, 4, 326-341. [CrossRef]

2. Fridlyander, I.N. Current-Technology Aluminum Alloys for Aerospace Applications (Abstract). Met. Sci. Heat Treat. $2001,43,297$. [CrossRef]

3. Kaibyshev, O.A. Superplasticity of Alloys. In Intermetallides and Ceramics; Springer: Berlin/Heidelberg, Germany, 1992; Volume 2, pp. $40-45$.

4. Kaibyshev, R.; Shipilova, K.; Musin, F.; Motohashi, Y. Continuous dynamic recrystallization in an Al-Li-Mg-Sc alloy during equal-channel angular extrusion. Mat. Sci. Eng. A Struct. 2005, 396, 341-351. [CrossRef]

5. Bolt, P.; Lamboo, N.; Rozier, P. Feasibility of warm drawing of aluminium products. J. Mater. Process. Technol. 2001, 115, 118-121. [CrossRef]

6. Nieh, T.G.; Wadsworth, J.; Sherby, O.D. Superplasticity in Metals and Ceramics. In Superplasticity in Metals and Ceramics; Amsterdam University Press: Amsterdam, The Netherlands, 1997; Volume 3, pp. 26-35.

7. Ye, L.Y.; Zhang, X.M.; Zheng, D.W.; Liu, S.D.; Tang, J.G. Superplastic behavior of an Al-Mg-Li alloy. J. Alloy Compd. 2009, 487, 109-115. [CrossRef]

8. Zhang, X.M.; Zheng, D.W.; Ye, L.Y.; Tang, J.G. Superplastic deformation behavior and mechanism of 1420 Al-Li alloy sheets with elongated grains. J. Central South Univ. Technol. 2010, 17, 659-665. [CrossRef]

9. Bhatta, L.; Pesin, A.; Zhilyaev, A.P.; Tandon, P.; Kong, C.; Yu, H. Recent Development of Superplasticity in Aluminum Alloys: A Review. Metals 2020, 10, 77. [CrossRef] 
10. Zhang, Y.; Hou, H.; Bi, J.; Wang, Y. Influence of Pulsed Current on Superplasticity of Fine Grained 1420 Al-Li Alloy. IOP Conf. Ser. Mater. Sci. Eng. 2018, 301, 2080. [CrossRef]

11. Myshlyaev, M.M.; Gryaznov, M.Y.; Chuvildeev, V.N. Superplasticity of an aluminum-lithium 1420 alloy in various structural states. Russ. Met. 2011, 2011, 882-888. [CrossRef]

12. Dutkiewicz, J.; Kalita, D.; Maziarz, W.; Tański, T.; Faryna, M. Effect of KOBO Extrusion and Following Cyclic Forging on Grain Refinement of Mg-9Li-2Al-0.5Sc Alloy. Met. Mater. Int. 2019, 26, 1004-1014. [CrossRef]

13. Mukhopadhyay, A.K.; Kumar, A.; Raveendra, S.; Samajdar, I. Development of grain structure during superplastic deformation of an Al-Zn-Mg-Cu-Zr alloy containing Sc. Scr. Mater. 2011, 64, 386-389. [CrossRef]

14. Lee, S.; Utsunomiya, A.; Akamatsu, H.; Neishi, K.; Furukawa, M.; Horita, Z.; Langdon, T.G. Influence of scandium and zir-conium on grain stability and superplastic ductilities in ultrafine-grained Al-Mg alloys. Acta Mater. 2002, 50, 553-564. [CrossRef]

15. Kumar, A.; Mukhopadhyay, A.K.; Prasad, K.S. Superplastic behaviour of Al-Zn-Mg-Cu-Zr alloy AA7010 containing Sc. Mat. Sci. Eng. A Struct. 2010, 527, 854-857. [CrossRef]

16. Mcqueen, H.J.; Evangelista, E. Hot Working Defines Thermomechanical Processing (TMP) for Aluminum Alloys and Compo-sites. Mater. Sci. Forum 2012, 706, 89-96. [CrossRef]

17. Solerød, H.; Jensrud, O.; Pedersen, K.O. New Development of Thermomechanical Processing (TMP) and High Volume Production Aluminium Wheel Suspension Arms. SAE Tech. Pap. Ser. 2001, 33, 323-325. [CrossRef]

18. Xiang, H.; Pan, Q.; Yu, X.; Huang, X.; Sun, X.; Wang, X.; Li, M.; Yin, Z. Superplasticity behaviors of Al-Zn-Mg-Zr cold-rolled alloy sheet with minor Sc addition. Mater. Sci. Eng. A 2016, 676, 128-137. [CrossRef]

19. Bate, P.S.; Ridley, N.; Zhang, B. Mechanical behaviour and microstructural evolution in superplastic Al-Li-Mg-Cu-Zr AA8090. Acta Mater. 2007, 55, 4995-5006. [CrossRef]

20. Kaibyshev, R.; Avtokratova, E.; Apollonov, A.; Davies, R. High strain rate superplasticity in an Al-Mg-Sc-Zr alloy subjected to simple thermomechanical processing. Scr. Mater. 2006, 54, 2119-2124. [CrossRef]

21. Langdon, T.G. Seventy-five years of superplasticity: Historic developments and new opportunities. J. Mater. Sci. 2009, 44, 5998-6010. [CrossRef]

22. Zhang, W.J.; Liu, H.H.; Ding, H.; Fujii, H. Grain refinement and superplastic flow in friction stir processed Ti-15V-3Cr-3Sn-3Al alloy. J. Alloy Compd. 2019, 803, 901-911. [CrossRef]

23. Backofen, W.A. Superplasticity in an Al-Zn Alloy. Trans. Asm. 1964, 57, 980-990.

24. Li, S.; Huang, Z.; Jin, S. Superplastic Behavioral Characteristics of Fine-Grained 5A70 Aluminum Alloy. Methods 2019, 9 , 62. [CrossRef]

25. Doherty, R.; Hughes, D.; Humphreys, F.; Jonas, J.; Jensen, D.; Kassner, M.; King, W.; McNelley, T.; McQueen, H.; Rollett, A. Current issues in recrystallization: A review. Mater. Sci. Eng. A 1997, 238, 219-274. [CrossRef]

26. Liu, F.; Xue, P.; Ma, Z. Microstructural evolution in recrystallized and unrecrystallized Al-Mg-Sc alloys during superplastic deformation. Mater. Sci. Eng. A 2012, 547, 55-63. [CrossRef]

27. Sakai, G.; Horita, Z.; Langdon, T.G. Grain refinement and superplasticity in an aluminum alloy processed by high-pressure torsion. Mater. Sci. Eng. A 2005, 393, 344-351. [CrossRef]

28. Lyttle, M.T.; Wert, J.A. Modelling of continuous recrystallization in aluminium alloys. J. Mater. Sci. 1994, 29, 3342-3350. [CrossRef]

29. Zhang, P.; Ye, L.Y.; Zhang, X.M.; Gu, G.; Jiang, H.C.; Wu, Y.L. Grain structure and microtexture evolution during superplastic deformation of 5A90 Al-Li alloy. Trans. Nonferrous Met. Soc. China 2014, 24, 2088-2093. [CrossRef]

30. Zhang, W.; Liu, H.; Ding, H.; Fujii, H. Superplastic deformation mechanism of the friction stir processed fully lamellar Ti-6Al-4V alloy. Mater. Sci. Eng. A 2020, 785, 9390. [CrossRef]

31. Zhang, X.; Tan, M.J. Dislocation Model for Continuous Recrystallisation during Initial Stage of Superplastic Deformation. Scr. Mater. 1998, 38, 827-831. [CrossRef]

32. McNelley, T.R.; Swisher, D.L.; Prado, P.M.T. Deformation bands and the formation of grain boundaries in a superplastic aluminum alloy. Met. Mater. Trans. A 2002, 33, 279-290. [CrossRef]

33. Tsuzaki, K.; Huang, X.; Maki, T. Mechanism of dynamic continuous recrystallization during superplastic deformation in a microduplex stainless steel. Acta Mater. 1996, 44, 4491-4499. [CrossRef]

34. Gourdet, S.; Montheillet, F. A model of continuous dynamic recrystallization. Acta Mater. 2003, 51, 2685-2699. [CrossRef]

35. Zhang, W.; Ding, H.; Cai, M.; Yang, W.; Li, J. Ultra-grain refinement and enhanced low-temperature superplasticity in a friction stir-processed Ti-6Al-4V alloy. Mater. Sci. Eng. A 2018, 727, 90-96. [CrossRef]

36. Zhang, W.J.; Liu, H.H.; Ding, H.; Fujii, H. The optimal temperature for enhanced low-temperature superplasticity in fi-ne-grained Ti-15V-3Cr-3Sn-3Al alloy fabricated by friction stir processing. J. Alloy Compd. 2020, 832, 4917. [CrossRef]

37. Sotoudeh, K.; Bate, P. Diffusion creep and superplasticity in aluminium alloys. Acta Mater. 2010, 58, 1909-1920. [CrossRef] 